\title{
Crohn's disease of the mouth: an indicator of intestinal involvement
}

\author{
C SCULLY, K M COCHRAN, R I RUSSELL, M M FERGUSON, M A K GHOURI, F D LEE, \\ D G MacDONALD, AND P B McINTYRE
}

From the University Department of Oral Medicine and Pathology, Glasgow Dental Hospital, Glasgow; Gastroenterology Unit, Victoria Infirmary, Glasgow, and Gastroenterology Unit, Royal Infirmary, Glasgow

SUMmaRY Niñeteen patients with clinical evidence of oral Crohn's disease but no intestinal symptoms were studied. Oral lesions in all patients were shown histologically to have lymphoedema with or without chronic granulomas consistent with Crohn's disease. Seven patients (37\%) had demonstrable intestinal disease on rectal biopsy and four of these had abnormal bowel radiology. All seven had evidence of nutritional deficiency. Patients with clinical features suggesting oral Crohn's disease may have evidence of Crohn's disease in the intestine, although this may not be clinically apparent.

Crohn's disease, originally described as a disorder of the small intestine, ${ }^{1}$ is now recognised to extend well beyond these confines ${ }^{2}$ and to involve all parts of the gastrointestinal tract, including the mouth. ${ }^{3}$ Clinical features suggestive of oral Crohn's disease include facial or labial swelling, angular cheilitis, mucosal tags or cobblestoning of the oral mucosa, hyperplastic gingival lesions, and oral ulcers. 4 Early reports of oral Crohn's disease were usually of patients with symptomatic gastrointestinal Crohn's disease but Varley described three patients with oral Crohn's disease who had no intestinal symptoms and Taylor and Smith ${ }^{6}$ reported a patient with oral Crohn's disease who, on the basis of contrast radiography, sigmoidoscopy, and nutritional status, had no intestinal involvement. Tyldesley ${ }^{4}$ reported six patients with oral Crohn's disease who failed to develop gastrointestinal symptoms during a five year follow-up, although one of the patients had iron deficiency of unknown aetiology.

The lesions of oral Crohn's disease histologically resemble those of intestinal Crohn's disease with lymphoedema of the lamina propria and small numbers of non-caseating granulomas. The aim of this investigation was to examine patients with this type of lesion of the oral mucosa, who had no symptoms of intestinal disease, for evidence of intestinal lesions in order to assess the importance of such oral lesions as indicators of intestinal Crohn's disease.

Received for publication 10 September 1981

\section{Methods}

\section{PATIENTS}

The details of the study group and presenting features are shown in Table 1.

The group consisted of nine males and 10 females (age range 3-40 years: median age 15.0 years) presenting at the Oral Medicine Clinic with clinical features suggestive of oral Crohn's disease who, on biopsy of the affected oral mucosa, showed characteristic granulomatous changes and/or lymphoedema.

The oral biopsies in all cases showed lymphoedema with dilated lymphatics in the lamina propria, although this varied in severity between cases. Granulomas with epithelioid cells and multinucleated giant cells were seen in 14 cases but neither caseation necrosis nor acid-alcohol fast bacilli were demonstrable. Three cases showed focal collections of lymphocytes and epithelioid histiocytes, usually related to lymphatic vessels but a focal inflammatory infiltrate was absent in the remaining two cases.

Only those patients who had no historical evidence of gastrointestinal disease were included in this study.

Gastrointestinal assessment was undertaken at a variable interval after the onset of oral lesions (time interval median one year: range one month to 11 years) and included a detailed history, physical examination including sigmoidoscopy, and a range of investigations including full blood count, erythrocyte sedimentation rate, serum vitamin $B_{12}$, corrected whole blood folate, serum iron and total iron binding capacity, urea and electrolytes, liver function tests, serum calcium, 
Table 1 Characteristics of study group

\begin{tabular}{|c|c|c|c|c|c|c|}
\hline \multirow{2}{*}{$\begin{array}{l}\text { Patient } \\
\text { no. }\end{array}$} & \multirow{2}{*}{$\begin{array}{l}\text { Age }(y r) \\
\text { sex }\end{array}$} & \multicolumn{4}{|c|}{ Oral lesions } & \multirow{2}{*}{$\begin{array}{l}\text { Duration } \\
(y r)\end{array}$} \\
\hline & & Swelling & $\begin{array}{l}\text { Mucosal tags or } \\
\text { cobblestoning }\end{array}$ & Ulcers & $\begin{array}{l}\text { Angular } \\
\text { cheilitis }\end{array}$ & \\
\hline $\begin{array}{l}1 \\
2 \\
3 \\
4 \\
5 \\
6 \\
7 \\
8 \\
9 \\
10 \\
11 \\
12 \\
13 \\
14 \\
15 \\
16 \\
17 \\
18^{*} \\
19\end{array}$ & $\begin{array}{r}8 \mathrm{~F} \\
21 \mathrm{~F} \\
13 \mathrm{~F} \\
15 \mathrm{~F} \\
40 \mathrm{~F} \\
22 \mathrm{~F} \\
15 \mathrm{~F} \\
17 \mathrm{~F} \\
13 \mathrm{~F} \\
10 \mathrm{~F} \\
21 \mathrm{M} \\
10 \mathrm{M} \\
9 \mathrm{M} \\
13 \mathrm{M} \\
3 \mathrm{M} \\
10 \mathrm{M} \\
34 \mathrm{M} \\
32 \mathrm{M} \\
33 \mathrm{M}\end{array}$ & $\begin{array}{l}+ \\
+ \\
+ \\
+ \\
+ \\
+ \\
+ \\
+ \\
+ \\
+ \\
+ \\
+ \\
+ \\
+ \\
+ \\
+ \\
+ \\
+ \\
-\end{array}$ & $\begin{array}{l}\bar{t} \\
+ \\
\bar{t} \\
\bar{t} \\
\bar{t} \\
\bar{t} \\
+ \\
+ \\
+ \\
+ \\
- \\
- \\
- \\
\bar{t}\end{array}$ & $\begin{array}{l}- \\
\bar{t} \\
+ \\
- \\
\bar{t} \\
- \\
- \\
- \\
- \\
- \\
- \\
+ \\
+ \\
+ \\
+ \\
\bar{t}\end{array}$ & $\begin{array}{l}+ \\
\bar{t} \\
- \\
- \\
\bar{t} \\
- \\
+ \\
- \\
- \\
- \\
- \\
+ \\
- \\
+ \\
+ \\
- \\
-\end{array}$ & $\begin{array}{l}8 / 12 \\
1 \\
3 / 12 \\
1 \\
1 \\
1 / 12 \\
1 \\
3 \\
31 / 2 \\
3 / 12 \\
11 \\
1 / 12 \\
3 \\
3 / 12 \\
3 / 12 \\
11 / 2 \\
6 \\
8 / 12 \\
2^{1 / 2}\end{array}$ \\
\hline
\end{tabular}

* Melkersson-Rosenthal syndrome $+=$ lesion present, $-=$ lesion absent.

phosphate, zinc, magnesium, and immunoglobulin concentrations.

Radiological examinations of the small and large intestine and chest were performed in all patients. Rectal biopsy was carried out in all patients and jejunal biopsy, Kveim, and Mantoux tests, were performed where clinically indicated.

The colorectal and intestinal biopsies were processed, orientated and stained by routine methods and in most cases multiple ribbon sections were prepared and examined.

\section{Results}

The 19 patients were selected on the basis of oral lesions clinically and histologically consistent with a diagnosis of oral Crohn's disease. Sixteen of the 19 patients had recurrent facial or labial swelling (one had the Melkersson-Rosenthal syndrome of facial swelling, scrotal tongue, and facial palsy) and 10 had mucosal tags or cobblestoning of the mucosa. Oral ulceration $(8 / 19)$ was aphthous in type (6) or sometimes persistent linear ragged ulcers in the buccal vestibule (2). Seven patients had angular cheilitis. There appeared, however, to be no consistent correlation of particular oral manifestations.

The medical histories and general physical examination, including sigmoidoscopy, failed to reveal significant systemic abnormalities in any patient.

In none of the small bowel biopsies was any abnormality of villous morphology detected and the cryptvillous ratio was always in the normal range (less than $0 \cdot 5)$. In only one case was there any abnormality of the leucocyte infiltrate in the lamina propria; in this instance, there was a villus swollen by a focal lymphoplasmacytic infiltration which was associated with mild damage to the overlying epithelium. Epithelioid granulomas were not, however, detected.

The colorectal biopsies occasionally showed nondiagnostic inflammatory changes in the lamina propria. Some of these changes were diffuse but tended more often to be patchy. Goblet cell depletion in the crypts was always minimal. Granulomas regarded as the only definitive (if not diagnostic) lesions in Crohn's disease were found in the lamina propria in seven cases: usually these were associated with mild non-specific infiltration in the lamina propria.

The results of investigations are shown in Tables 2 and 3. Seven of the patients were established as having intestinal lesions as a result of finding granulomas on rectal biopsy and intestinal disease was confirmed in four by abnormal findings on small bowel radiology or

Table 2 Results of biopsy and radiological examination in patients with oral granulomatous lesions with intestinal involvement

\begin{tabular}{lllll}
\hline Patient & \multicolumn{2}{l}{ Sigmoidoscopy Rectal biopsy } & $\begin{array}{l}\text { Small bowel } \\
\text { radiology }\end{array}$ & $\begin{array}{l}\text { Barium } \\
\text { enema }\end{array}$ \\
\hline 2 & - & + & - & - \\
3 & - & + & - & - \\
4 & - & + & + & - \\
7 & - & + & - & - \\
13 & - & + & + & + \\
16 & - & + & - & + \\
19 & - & + & + & -
\end{tabular}

+: abnormalities indicative of intestinal disease, - : no abnormalities. 
Table 3 Results of haematological and nutritional examination in patients with oral granulomatous lesions with intestinal involvement

\begin{tabular}{|c|c|c|c|c|c|c|c|c|c|}
\hline \multirow{2}{*}{$\begin{array}{l}\text { Patient } \\
\text { no }\end{array}$} & \multirow{2}{*}{$\begin{array}{l}\text { Iron } \\
\text { deficiency or } \\
\text { iron } \\
\text { deficiency } \\
\text { anaemia* }\end{array}$} & \multirow{2}{*}{$\begin{array}{l}\text { Corrected } \\
\text { whole } \\
\text { blood folate } \\
(n g / m l)\end{array}$} & \multirow{2}{*}{$\begin{array}{l}\text { Serum } \\
\text { vitamin } B_{12} \\
(p g / m l)\end{array}$} & \multirow{2}{*}{$\begin{array}{l}\text { Erythrocyte } \\
\text { sedimenta- } \\
\text { tion rate } \\
(\mathrm{mm} / \mathrm{h})\end{array}$} & \multicolumn{5}{|c|}{ Serum levels of } \\
\hline & & & & & $\begin{array}{l}\text { Albumin } \\
(g / l)\end{array}$ & $\begin{array}{l}\text { Calciumt } \\
(\mathrm{mmol} / \mathrm{l})\end{array}$ & $\begin{array}{l}\text { Phosphate } \\
\text { (mmol/l) }\end{array}$ & $\begin{array}{l}\text { Zinc } \\
(\mu \mathrm{mol} / \mathrm{l})\end{array}$ & $\begin{array}{l}\text { Magnesium } \\
(\mu \mathrm{mol} / \mathrm{l})\end{array}$ \\
\hline $\begin{array}{l}2 \\
3 \\
4 \\
7 \\
13 \\
16 \\
19 \\
\text { Normal } \\
\text { values }\end{array}$ & $\begin{array}{l}+ \\
- \\
+ \\
+ \\
+ \\
\bar{t}\end{array}$ & $\begin{array}{l}115 \\
120 \\
192 \\
100 \\
110 \\
150 \\
95 \\
100-600\end{array}$ & $\begin{array}{l}440 \\
410 \\
295 \\
320 \\
590 \\
420 \\
635 \\
240-1000\end{array}$ & $\begin{array}{l}9 \\
18 \\
37 \\
15 \\
22 \\
15 \\
8 \\
0-10\end{array}$ & $\begin{array}{l}40 \\
27 \\
33 \\
36 \\
27 \\
26 \\
42 \\
38-53\end{array}$ & $\begin{array}{l}2 \cdot 2 \\
2 \cdot 5 \\
2 \cdot 3 \\
2 \cdot 2 \\
1 \cdot 9 \\
2 \cdot 4 \\
2 \cdot 4 \\
2 \cdot 3-2 \cdot 6\end{array}$ & $\begin{array}{l}0.9 \\
0.9 \\
0.7 \\
1.1 \\
0.9 \\
1.0 \\
1.1 \\
0.8-1.5\end{array}$ & $\begin{array}{c}13 \cdot 2 \\
11 \cdot 3 \\
10 \cdot 3 \\
14 \cdot 5 \\
9 \cdot 0 \\
14 \cdot 1 \\
13 \cdot 7 \\
12-18\end{array}$ & $\begin{array}{l}0.90 \\
0.81 \\
0.74 \\
0.98 \\
0.91 \\
0.82 \\
0.88 \\
0.75-1.0\end{array}$ \\
\hline
\end{tabular}

* Iron deficiency (transferrin saturation [serum iron/total iron binding capacity] below 16\%) or iron deficiency anaemia.

+ Deficiency or anaemia present.

- No deficiency or anaemia.

$\uparrow$ Corrected for albumin level.

barium enema (Table 2). Interestingly, none of these patients had abnormal sigmoidoscopic findings. Those patients with intestinal disease also had anaemia, raised erythrocyte sedimentation rate (ESR) or reduced serum albumin, each of which was found in five patients, but only three of the seven patients with intestinal disease had abnormalities in all three of these parameters. The ESR was raised in five patients, all of whom had a reduced serum albumin concentration. Five of the seven patients with rectal granulomas had iron deficiency anaemia and two of these were also marginally low in folate. Serum vitamin $B_{12}$ levels, however, were normal in all. Occasional findings included a reduced serum calcium, phosphate, zinc, or magnesium, but serum immunoglobin levels were normal (Table 3).

There was no particular sex predilection in the patients who proved to have intestinal disease (four females and three males) and the age distribution of this group (median 15 years: range 9 to 33 years) was comparable with those having no intestinal disease (median 15 years: range 3 to 40 years). Furthermore, the delay between onset of oral lesions and investigation for intestinal disease in those with intestinal involvement (median one year: range three months to three years) was not longer than in those without intestinal lesions (median eight months: range one month to 11 years).

One other patient in the study group was diagnosed as having sarcoidosis on the basis of a rash, positive Kveim test, and a raised ESR. Of the 12 patients with normal rectal biopsy, three (patients number 1,5 , and 15) had a haemoglobin of $10.6 \mathrm{~g} / \mathrm{dl}$ in each instance, but no evidence of malabsorption. The delay between onset of oral lesions and investigation of these three patients for intestinal disease was three months to one year (median eight months).

\section{Discussion}

These results indicate that $37 \%(7 / 19)$ of patients who had presented solely with features suggestive of oral Crohn's disease had asymptomatic intestinal involvement established by rectal biopsy and supported by finding nutritional defects, raised erythrocyte sedimentation rates, and abnormal bowel radiology.

All patients presented with oral or facial swellings, mucosal tags or cobblestoning, oral ulcers, or features of angular cheilitis previously defined as suggestive of oral Crohn's disease. ${ }^{4}$ All had facial swellings, mucosal tags, or cobblestoning. Oral ulceration was persistent or recurrent in $42 \%(8 / 19)$ patients and $37 \%(7 / 19)$ had angular cheilitis. The latter is more commonly found in older patients usually related to Candidal infection beneath an upper denture.

It is interesting to note that the group of patients with intestinal lesions did not appear to differ significantly from those without intestinal disease with respect to sex predilection, age, or duration of oral lesions. In the group with intestinal disease the lesions appeared within three months to three years; only three of the patients without established intestinal disease have had oral lesions in excess of this time and it is impossible to predict whether any of this group will manifest intestinal involvement at a later stage, although the finding of low haemoglobin in three patients might be an early indication of intestinal disease.

It is well established that oral lesions can occur in patients with intestinal Crohn's disease. Croft and Wilkinson in $1972^{7}$ reviewed retrospectively 332 cases of intestinal Crohn's disease and found that $6 \%$ had oral ulceration at some stage of the illness, and a similar prevalence (9\%) was found by Basu et al. in 1975 in a study of 100 patients with intestinal Crohn's disease. ${ }^{8}$ Oral lesions in intestinal Crohn's disease have not con- 
sistently been related to the severity or extent of intestinal involvement and have been reported to appear before or after the onset of gastrointestinal symptoms. However, a review of reports of 24 patients with oral involvement in intestinal Crohn's disease revealed that the oral lesions had preceded the diagnosis of intestinal involvement in over $30 \%$, although bowel symptoms were usually evident within a few months of the onset of oral lesions - the longest time interval being one year. ${ }^{9}$ The present results are quite consistent with this pattern of events. Extraintestinal Crohn's disease in other sites such as the anus may also precede the development of intestinal symptoms, in that instance by several years. ${ }^{10}$ It is also becoming apparent that uncommon oral disorders such as the MelkerssonRosenthal syndrome and cheilitis granulomatosa closely resemble oral Crohn's disease, sarcoidosis, or tuberculosis clinically and histologically ${ }^{11-13}$ and may precede intestinal Crohn's disease. ${ }^{414} 15$

The results of the present study suggest that, as over $35 \%$ of patients with clinical and histological features consistent with oral Crohn's disease but who were otherwise asymptomatic had intestinal involvement and also had complications such as anaemia or nutritional deficiencies, all patients with oral Crohn's disease should be screened haematologically with particular attention to the full blood picture: haemoglobin, and red cell indices; iron and folate studies; erythrocyte sedimentation rate: and serum albumin levels. Rectal biopsy followed by bowel radiology is required for definitive assessment of intestinal involvement. Other causes of granulomas must be excluded.

It will be interesting to observe the subsequent progress of those patients who have, at this time, no clinical or laboratory evidence of gastrointestinal disease.

Our thanks are to the various colleagues who have referred their patients to us.

\section{References}

1 Crohn BB, Ginzburg L, Oppenheimer GD. Regional lleitis: a pathologic and clinical entity. JAMA 1932; 99:1323-8.

2 Greenstein AJ, Janowitz HD, Sachar DB. The extra intestinal complications of Crohn's disease and ulcerative colitis. Medicine 1976; 55:401-12.

3 Dudeney, TP and Todd IP. Crohn's disease of the mouth. Proc $R$ Soc Med 1969; 62:1237.

4 Tyldesley WR. Oral Crohn's disease and related conditions. Br J Oral Surg 1979; 17:1-9.

5 Varley EWB. Crohn's disease of the mouth: report of three cases. Oral Surg 1972; 33:570-8.

6 Taylor VE, Smith CJ. Oral manifestations of Crohn's disease without demonstrable gastrointestinal lesions. Oral Surg 1975; 39:58-66.

7 Croft CB, Wilkinson AR. Ulcerations of the mouth, pharynx and larynx in Crohn's disease of the intestine. Br J Surg 1972; 59:249-52.

8 Basu MK, Asquith P, Thompson RA, Cooke WT. Oral manifestations of Crohn's disease. Gut 1975; 16:249-54.

9 Bernstein ML, MacDonald JS. Oral lesions in Crohn's disease: report of two cases and update of the literature. Oral Surg 1978; 46:234-45.

10 Baker NW, Milton-Thompson GJ, Lockhart-Mummery HE. The anal lesion as the sole presenting symptom of intestinal Crohn's disease. Gut 1971; 12:865.

11 Meischer G. Uber essetielle granulomatose Makrocheilie (Cheilitis granulomatosa). Dermatologica 1945; 91:57-85.

12 Bazex A, Dupre A. Les infiltrations lymphoedematenses, sarcoidiques et adenomateuses chroniques du visage (syndrome de Melkersson-Rosenthal, fibroedemede Stevens syndrome d'Ascher). Toulouse Med 1957; 58:89-109.

13 Dahm G, Schinko H. Zur genese der cheilitis granulomatosa bzw des Melkersson-Rosenthal syndrome. Arch Klin Exp Derm 1961; 212:616-37.

14 Carr D. Granulomatous cheilitis in Crohn's disease. $\mathrm{Br}$ Med J 1974; 4:636.

15 Tondbury, GD. Cheilitis granulomatosa Und Morbus Crohn. Praxis 1977; 66:792. 